\title{
Selection of Infective Arbuscular Mycorrhizal Fungal Isolates for Field Inoculation
}

\author{
Elisa Pellegrino ${ }^{1}$, Chandra Kamatchi Ramasamy ${ }^{1}$, Cristiana Sbrana ${ }^{2}$, Paolo Barberi ${ }^{1}$, \\ Manuela Giovannetti*3 \\ ${ }^{1}$ Land Lab, Sant'Anna School of Advanced Studies, Piazza Martiri della Libertà 33, 56127 Pisa, Italy \\ ${ }^{2}$ Institute of Biology and Agricultural Biotechnology, U.O. Pisa, CNR, Via del Borghetto 80, 56124 Pisa, Italy \\ ${ }^{3}$ Department of Crop Plant Biology, University of Pisa, Via del Borghetto 80, 56124 Pisa, Italy
}

Received: 14 September 2009. Accepted: 17 November 2009.

\begin{abstract}
Arbuscular mycorrhizal (AM) fungi play a key role in host plant growth and health, nutrient and water uptake, plant community diversity and dynamics. AM fungi differ in their symbiotic performance, which is the result of the interaction of two fungal characters, infectivity and efficiency. Infectivity is the ability of a fungal isolate to establish rapidly an extensive mycorrhizal symbiosis and is correlated with pre-symbiotic steps of fungal life cycle, such as spore germination and hyphal growth. Here, different AM fungal isolates were tested with the aim of selecting infective endophytes for field inoculation. Greenhouse and microcosm experiments were performed in order to assess the ability of 12 AM fungal isolates to produce spores, colonize host roots and to perform initial steps of symbiosis establishment, such as spore germination and hyphal growth. AM fungal spore production and root colonization were significantly different among AM fungal isolates. Spore and sporocarp densities ranged from 0.8 to 7.4 and from 0.6 to 2.0 per gram of soil, respectively, whereas root colonization ranged from 2.9 to $72.2 \%$. Percentage of spore or sporocarp germination ranged from 5.8 to $53.3 \%$ and hyphal length from 4.7 to $79.8 \mathrm{~mm}$. The ordination analysis (Redundancy Analysis, RDA) showed that AM fungal isolates (used as explanatory variables) explained about $60 \%$ of the whole variance and their effect on fungal infectivity variables was significant $(P=$ 0.002). The biplot clearly showed that variables which might be used to detect infective AM fungal isolates were hyphal length and root colonization. Such analysis may allow the detection of the best parameters to select efficient AM fungal isolates to be used in agriculture.
\end{abstract}

Key-words: arbuscular mycorrhizas, hyphal length, root colonization, spore germination, AM fungal infectivity, sporulation.

\section{Introduction}

Arbuscular mycorrhizas are mutualistic associations between the roots of about $80 \%$ of plant species and soil fungi of the phylum Glomeromycota (about 150 species) (Schüßler and Schwarzott, 2001; Smith and Read, 2008). Fungal hyphae spread into the soil from mycorrhizal roots and improve the uptake effectiveness of poorly mobile nutrients such as $\mathrm{P}, \mathrm{Zn}$ and $\mathrm{Cu}$ and of mineral forms of $\mathrm{N}$ and $\mathrm{K}$. The enhanced nutrient uptake by mycorrhizal plants compared to non-mycorrhizal plants is due to fungal hyphae that grow beyond the area of root nutri- ent depletion and within soil micropores, increasing the absorbing surface and the access to inorganic and organic forms of $\mathrm{P}$ and $\mathrm{N}$. Moreover, arbuscular mycorrhizal (AM) fungi provide protection to host plant against root and shoot pathogens (Newsham et al., 1995). AM fungal symbionts are obligate biotrophs and, after establishing functional symbioses with host plants, produce spores in the soil which are able to germinate and grow, but are unable to produce extensive mycelia and to complete their life cycle in the absence of their hosts (Giovannetti and Avio, 2002). Although AM symbionts cannot be grown in axenic culture and

\footnotetext{
* Corresponding Author: Tel.: +39 050 2216643; Fax: +39 050571562 . E-mail address: mgiova@agr.unipi.it
} 
knowledge of their biology is limited, some of the factors affecting their development have been studied (Giovannetti and Avio, 2002). Because of the complexity of the interactions between fungal isolates and host/soil/environmental factors, no generalization is possible. Nevertheless, the criteria to be followed for the selection of suitable endophytes is the result of the interaction of two fundamental characters, infectivity and efficiency.

Infectivity has been defined as the ability of a fungal isolate to establish rapidly an extensive mycorrhizal colonization in the roots of a host plant and is correlated with complex soil-fungus-host factors affecting fungal life cycle stages, i.e. spore germination, non symbiotic germling growth, host recognition, differentiation of infection structures and root colonization (Giovannetti and Gianinazzi-Pearson, 1994). The efficiency of different fungal endophytes cannot be measured simply in terms of host growth responses, since many factors, such as the uptake of $\mathrm{P}$ and other poorly mobile nutrients, linked to extraradical fungal networks development in the soil and to the rate of $\mathrm{P}$ adsorption, translocation and transfer from hyphae to host cells, contribute to determine their symbiotic performance (Giovannetti and Avio, 2002).

Field utilization of AM fungi depends primarily on the availability of highly infective isolates. Although different kinds of fungal propagules may affect infectivity, most studies have investigated the ecology and physiology of spores, as they represent the most frequently used propagules in laboratory and field experiments.
Therefore the parameters to be taken into account when selecting for infectivity mainly concern spore-related factors such as spore germination, pre-symbiotic growth of spore germlings and intraradical growth.

Here, different AM fungal isolates were tested, with the aim of detecting the best parameters allowing the selection of infective endophytes for field inoculation.

\section{Materials and methods}

\section{Fungal material}

Twelve AM fungal isolates were used as fungal material. Details of the isolates are given in Table 1.

\section{Greenhouse experiment}

This experiment allowed the assessment of the ability to produce spores and colonize host roots of the AM fungal isolates tested.

Experimental setup. Seeds of Medicago sati$v a \mathrm{cv}$. Messe and Trifolium alexandrinum cv. Tigri were sown in $600 \mathrm{ml}$ plastic pots containing a mixture (270:270 ml) of soil and Terragreen (calcinated clay, OILDRI, Chicago, IL, USA). The mixture was steam-sterilized to kill naturally occurring AM fungi. Pots were inoculated with $60 \mathrm{ml}$ of crude inoculum (mycorrhizal roots and soil containing spores and extraradical mycelium) of one of the 12 fungal isolates. In this way, possible differences in AM fungal colonization ability of the 12 isolates were balanced by using such high amounts of inoculum ( $10 \%$ by volume). All the pots received $100 \mathrm{ml}$

Table 1. Geographic origin and inoculum source of AM fungal isolates used in the present work.

\begin{tabular}{lllll}
\hline Fungal Species & Isolate code ${ }^{\mathrm{a}, \mathrm{b}}$ & Geographic origin & Donor & Original inoculum supplier \\
\hline Acaulospora spinosa & MN405D & Minnesota, USA & H. Gamper & INVAM, Morgantown, W. Va. \\
Glomus caledonium & IMA2 = BEG20 & Hartfordshire, UK & M. Giovannetti & Rothamsted, Exp. St., UK \\
Glomus clarum & FL979A & Florida, USA & H. Gamper & INVAM, Morgantown, W. Va. \\
Glomus coronatum & IMA3 = BEG28 & Tuscany, Italy & M. Giovannetti & IMA, Pisa, Italy \\
Glomus etunicatum & UK208 & UK & H. Gamper & INVAM, Morgantown, W. Va. \\
Glomus geosporum & CI102 & China & H. Gamper & INVAM, Morgantown, W. Va. \\
Glomus mosseae & BEG25 & West Sussex, UK & M. Giovannetti & IIB, Canterbury, UK \\
Glomus mosseae & FL156 & Florida, USA & M. Giovannetti & INVAM, Morgantown, W. Va. \\
Glomus mosseae & IMA1 & Kent, UK & M. Giovannetti & Rothamsted, Exp. St., UK \\
Glomus mosseae & NB114 & Namibia & M. Giovannetti & INVAM, Morgantown, W. Va. \\
Glomus spp. & AD 1 & Abu Dhabi & M. Giovannetti & IIB, Canterbury, UK \\
Scutellospora calospora & NC128 & N. Caroline, USA & H. Gamper & INVAM, Morgantown, W. Va. \\
\hline
\end{tabular}

${ }^{\mathrm{a} B E G}$, Bank of European Glomales; ' IMA, International Microbial Archives; ${ }^{\mathrm{c}} \mathrm{Abbreviations:} \mathrm{INVAM,} \mathrm{International} \mathrm{Culture} \mathrm{Col-}$ lection of Arbuscular and Vesicular-Arbuscular Mycorrhizal Fungi; IIB, International Institute of Biotechnology. 
of a filtrate, obtained by sieving a mixture of the 12 inocula and of agricultural soil from $M$. sativa and $T$. alexandrinum fields, through a sieve with pore diameter of $50 \mu \mathrm{m}$, to ensure a common microflora to all treatments. After emergence, seedlings of $M$. sativa and T. alexandrinum were thinned to 10. Plants were grown for three months in greenhouse, supplied with tap water as needed and fertilized with half-strength Hoagland's solution once a month. The experiment was a completely randomized design with 12 inoculum treatments (each fungal isolate) and 5 replicates.

Assessment of spore production and host root colonization. At harvest, three months after emergence, sporocarps and spores were extracted from a subsample of $50 \mathrm{~g}$ of soil by each pot culture $(n=5)$ by wet-sieving and decanting, down to a mesh size of $100 \mu \mathrm{m}$, flushed into Petri dishes, manually collected with forceps and counted under a Wild dissecting microscope (Leica, Milano, Italy). Mycorrhizal colonization were then assessed on root samples from each pot culture after clearing and staining (Phillips and Hayman, 1970), utilizing lactic acid instead of lactophenol, by using the gridline intersect method (Giovannetti and Mosse, 1980).

\section{Microcosm experiment}

This experiment allowed the assessment of the ability of the AM fungal isolates tested to perform initial steps of symbiosis establishment, such as spore germination and hyphal growth.

Experimental set-up. The experimental model is the 'sandwich system' devised for investigating the early stages of AM fungal life cycle (Giovannetti et al., 1993a). Sporocarps or single spores (at least 20 propagules for each membrane) were germinated in the dark at $24{ }^{\circ} \mathrm{C}$ between two 47-mm-diameter cellulose nitrate Millipore $^{\mathrm{TM}}$ membranes (pore diameter 0.45 $\mu \mathrm{m})$ placed on acid-washed, sterile quartz grit $(2-5 \mathrm{~mm})$ in 14-cm-diameter Petri dishes. The experiment was a completely randomized design with 12 inoculum treatments (each fungal isolate) and at least 5 replicates.

Assessment of spore and sporocarp germination and hyphal growth. Spore germination was assessed after 14 days by staining with $0.05 \%$ trypan blue in lactic acid, and mycelial length was measured under a Wild dissecting microscope by using the grid-line intersect method (Giovannetti and Mosse, 1980).

\section{Statistics and data analyses}

Data were compared using a one-way (fungal treatment as factor) analysis of variance (ANOVA). Data were $\ln$ - and arcsine-transformed when needed to fulfil the assumptions of the ANOVA, which was carried out according to a completely randomized design. Tukey B procedure was used for comparing means. All statistics were performed with the SPSS 17.0 software (SPSS Inc., Chicago, IL, USA). Means and standard errors (S.E.) given in tables are for untransformed data. Ordination analysis (Redundancy Analysis, RDA) was carried out in Canoco for Windows v. 4.5 (ter Braak and Smilauer, 2003) in order to investigate the influence of the AM fungal isolates (used as explanatory variables) on fungal physiological parameters (used as response variables).

\section{Results and discussion}

\section{Greenhouse experiment}

Assessment of spore production and host root colonization. Three month after inoculation, spore density ranged between $0.78 \pm 0.25$ and $7.43 \pm 1.20$ spores/g of soil (S. calospora $\mathrm{NC128}$ and G. Geosporum CI102, respectively) and the total mean was $3.51 \pm 0.47$ (Tab. 2). Numbers of spores per gram of soil of A. spinosa MN405B, G. caledonium IMA2 = BEG20, Glomus spp. AD 1 and S. calospora NC128 significantly differed from values assessed for $G$. geosporum CI102 $(P<0.01)$ (Tab. 2). Sporocarp density ranged between $0.63 \pm 0.23$ and $2.01 \pm 0.66$

Table 2. Number of spores of eight arbuscular mycorrhizal fungal isolates produced after three months in symbiosis with Medicago sativa and Trifolium alexandrinum.

\begin{tabular}{lc}
\hline Isolate & $\begin{array}{c}\text { Spore density } \\
(\mathrm{n} / \mathrm{g} \text { of soil) }\end{array}$ \\
\hline Acaulospora spinosa MN405B & $2.32 \pm 0.98^{\mathrm{a}} \mathrm{a}$ \\
Glomus caledonium IMA2=BEG20 & $2.67 \pm 0.65 \mathrm{a}$ \\
Glomus clarum FL979A & $\mathrm{n} \cdot \mathrm{a}^{\mathrm{b}}$ \\
Glomus coronatum IMA3=BEG28 & $3.88 \pm 0.61 \mathrm{ab}$ \\
Glomus etunicatum UK208 & $4.60 \pm 1.66 \mathrm{ab}$ \\
Glomus geosporum CI102 & $7.43 \pm 1.20 \mathrm{~b}$ \\
Glomus spp. AD 1 & $2.92 \pm 0.83 \mathrm{a}$ \\
Scutellospora calospora NC128 & $0.78 \pm 0.25 \mathrm{a}$ \\
\hline Total & $3.51 \pm 0.47$ \\
\hline
\end{tabular}

${ }^{a}$ Values are means \pm SE of five replicates for each treatment; values in the column not followed by the same letters are significantly different $(P<0.01)$; ${ }^{b}$ not assessed. 
spores/g of soil (G. mosseae FL156 and $G$. mosseae NB114, respectively) and total mean was $1.13 \pm 0.20$ (Tab. 3). Interestingly, significant intraspecific differences were observed between $G$. mosseae FL156 and G. mosseae NB114 $(P<0.05)$ (Tab. 3).

Our data on spore production were comparable to those obtained by Giovannetti et al. (1988) by using Glomus monosporum with Allium cepa and Trifolium pratense as host plants (0.6-3.7 spores/g of soil) and by Moreira et al. (2007) by using diverse AM fungi in symbiosis with different host plants (0.2-1.5 spores/g of soil). Differences in AM fungal sporulation have been reported by several authors when different plants were used as hosts, both in laboratory (Daft and Hogarth, 1983; Hetrick and Bloom, 1986; Koomen et al., 1987; Hung and Sylvia, 1988; Bever et al., 1996; Carrenho et al., 2002) and in field conditions (Black and Tinker, 1979; Schenck and Kinloch, 1980; McGraw and Hendrix, 1984; Moreira et al., 2007). Moreover, sporulation was significantly affected by harvest time (Bever et al., 1996), season (Fowler and Antonovics, 1981; Gemma et al., 1989; Bentivenga and Hetrick, 1991; Hetrick et al., 1994), edaphic factors (Gilden and Tinker, 1981; Stahl and Smith, 1984; Louis and Lim, 1988; Boerner, 1990; Stahl et al., 1990; Stahl and Christensen, 1991), and AM fungal geographic origin (Fox and Morrow, 1981; Burdon, 1987).

The low values of $S$. calospora spore production detected in this work were similar to those reported by Bever et al. (1996), ranging from 0.15 to 0.35 spores $/ g$ of soil. Other authors showed low (0.02-0.16 spores/g of soil) or no sporulation of different Scutellospora species (Bever et al., 1996; Moreira et al., 2007), suggesting possible sporulation difficulties of such genus in pot conditions.

The isolate of $A$. spinos $a$ utilised in our work produced a higher number of spores (2.3 spores/g of soil) compared to data reported for different isolates of Acaulospora spp., showing spore density values ranging from 0.002 to 0.17 spores/g of soil, in symbiosis with Panicum and Plantago in greenhouse conditions (Bever et al., 1996) and from 0.02 to 0.6 spores/g of soil, in symbiosis with Araucaria angustifolia in field conditions (Moreira et al., 2007).

G. etunicatum was shown to produce a high
Table 3. Number of sporocarp of four arbuscular mycorrhizal fungal isolates, belonging to Glomus mosseae species, produced after three months in symbiosis with Medicago sativa and Trifolium alexandrinum.

\begin{tabular}{lc}
\hline Isolate & $\begin{array}{c}\text { Sporocarp density } \\
\text { (n/g of soil) }\end{array}$ \\
\hline Glomus mosseae BEG25 & $0.90 \pm 0.09^{\mathrm{a}} \mathrm{ab}$ \\
Glomus mosseae FL156 & $0.63 \pm 0.23 \mathrm{a}$ \\
Glomus mosseae IMA1 & $0.97 \pm 0.05 \mathrm{ab}$ \\
Glomus mosseae NB114 & $2.01 \pm 0.66 \mathrm{~b}$ \\
\hline Total & $1.13 \pm 0.40$ \\
\hline
\end{tabular}

aalues are means \pm SE of five replicates for each treatment; values in the column not followed by the same letters are significantly different $(P<0.05)$.

number of spores/g of soil, ranging from 18.6 to 152.8 , in symbiosis with Panicum miliaceum, whereas lower values (from 0.22 to 1.54 spores/g of soil), comparable to spore densities reported by this work, were observed in symbiosis with Sorghum vulgare (Silva et al., 2005).

The high values of spore density detected here for G. geosporum are not comparable with those previously reported by Snyder et al. (2001).

G. mosseae, in associations with different cultivars of M. sativa and with Paspalum notatum, showed values of $1.32-3.65$ spores/g of soil (Douds et al., 1998), which were comparable with $G$. mosseae spore densities assessed here. Interestingly, in this work a variability within the worldwide distributed species G. mosseae was detected, suggesting that sporulation is not a species-level feature in AM fungi.

Percentages of root colonization ranged between $2.86 \pm 1.39$ and $72.17 \pm 6.03$ (S. calospora NC128 and G. clarum FL979A, respectively) and the total mean was $39.33 \pm 2.74$ (Tab. 4). Results allowed the discrimination of AM fungal isolates tested into three groups, with low, medium and high infectivity: S. calospora $\mathrm{NC128}$ (low infectivity); G. etunicatum UK208, G. mosseae IMA1, A. spinosa MN405B, G. caledonium IMA2 = BEG20, G. coronatum IMA3 = BEG28, G. mosseae FL156, G. mosseae NB114, G. geosporum $\mathrm{CI} 102$ and Glomus spp. AD 1 (medium infectivity); G. clarum FL979A and $G$. mosseae BEG25 (high infectivity) (Tab. 4). Interestingly, significant differences were also observed among G. mosseae isolates (Tab. 4).

Here, no correlation was found between spore density and root colonization (data not shown). 
Table 4. Percentage of root colonization of Medicago sativa and Trifolium alexandrinum grown for three months in symbiosis with twelve arbuscular mycorrhizal fungal isolates.

\begin{tabular}{lc}
\hline Isolate & $\begin{array}{c}\text { Root colonization } \\
(\%)\end{array}$ \\
\hline Acaulospora spinosa MN405B & $36.98 \pm 6.38 \mathrm{a} \mathrm{bc}$ \\
Glomus caledonium IMA2=BEG20 & $27.35 \pm 4.22 \mathrm{bc}$ \\
Glomus clarum FL979A & $72.17 \pm 6.03 \mathrm{~d}$ \\
Glomus coronatum IMA3=BEG28 & $41.24 \pm 2.65 \mathrm{bc}$ \\
Glomus etunicatum UK208 & $22.26 \pm 2.46 \mathrm{ab}$ \\
Glomus geosporum CI102 & $50.64 \pm 3.78 \mathrm{~cd}$ \\
Glomus mosseae BEG25 & $68.54 \pm 8.05 \mathrm{~d}$ \\
Glomus mosseae FL156 & $34.56 \pm 3.48 \mathrm{bc}$ \\
Glomus mosseae IMA1 & $24.17 \pm 5.13 \mathrm{ab}$ \\
Glomus mosseae NB114 & $42.00 \pm 4.34 \mathrm{bc}$ \\
Glomus spp. AD 1 & $49.17 \pm 5.84 \mathrm{~cd}$ \\
Scutellospora calospora NC128 & $2.86 \pm 1.39 \mathrm{a}$ \\
\hline Total & $39.33 \pm 2.74$ \\
\hline
\end{tabular}

aalues are means \pm SE of five replicates for each treatment; values in the column not followed by the same letters are significantly different $(P<0.001)$.

Although differences in AM fungal root colonization, when different plants were used as hosts in different edaphic conditions, have been reported by several authors (Giovannetti et al., 1988; van der Heejden and Sanders, 2002; Smith and Read, 2008), root colonization represents a fundamental parameter to be studied in order to detect the most infective endophytes for field inoculation.

In this work the high values of root colonization showed by $G$. mosseae BEG25 were comparable with the values reported by Hart and Reader (2001). By contrast, other isolates of G. mosseae, IMA1, FL156 and NB114, showed low root colonization. Intraspecific variability, reported by several authors for parameters related to infectivity and efficiency (Smith et al., 2000; Munkvold et al., 2004; Avio et al., 2006), suggested that root colonization might be related more to isolates than to species, as showed for $G$. intraradices species by Hart and Reader (2001). Results obtained in this work for A. spinosa are similar to those reported by Hart and Reader (2001) for the same species, whereas values found for G. geosporum, showing a medium-high infectivity, are not comparable.

\section{Microcosm experiment}

Assessment of spore and sporocarp germination and hyphal growth. Spores of A. spinosa, G. caledonium, G. coronatum and S. calospora did not germinate in our experimental conditions. Germination percentages ranged between 5.83 \pm 3.00 and $53.33 \pm 4.94$ (G. etunicatum UK208 and G. clarum FL979A, respectively) and the total mean, excluding the AM isolates showing no germination, was $22.71 \pm 2.72$ (Tab. 5). Glomus spp. AD 1, G. geosporum CI102, G. etunicatum UK208, G. mosseae FL156, G. mosseae IMA1 and $G$. mosseae NB114 were characterised by low germination percentages, whereas G. clarum FL979A, G. mosseae BEG25 showed high germination ability (Tab. 5).

Table 5. Percentage of spore or sporocarps germination and hyphal length per spore or sporocarp of twelve arbuscular mycorrhizal fungal isolates.

\begin{tabular}{lcc}
\hline Isolate & $\begin{array}{c}\text { Percentage of germination } \\
(\%)\end{array}$ & $\begin{array}{c}\text { Hyphal length per spore } \\
\text { or sporocarp }(\mathrm{mm})\end{array}$ \\
\hline Acaulospora spinosa MN405B & 0 & - \\
Glomus caledonium IMA2=BEG20 & 0 & - \\
Glomus clarum FL979A & $53.33 \pm 4.94^{\mathrm{a}} \mathrm{d}$ & $31.16 \pm 4.00^{\mathrm{b}} \mathrm{ab}$ \\
Glomus coronatum IMA3=BEG28 & 0 & - \\
Glomus etunicatum UK208 & $5.83 \pm 3.00 \mathrm{a}$ & $36.22 \pm 35.17 \mathrm{a}$ \\
Glomus geosporum CI102 & $12.50 \pm 3.35 \mathrm{ab}$ & $12.09 \pm 3.14 \mathrm{ab}$ \\
Glomus mosseae BEG25 & $41.67 \pm 2.79 \mathrm{~cd}$ & $79.81 \pm 9.73 \mathrm{~b}$ \\
Glomus mosseae FL156 & $10.00 \pm 1.83 \mathrm{ab}$ & $4.67 \pm 1.41 \mathrm{a}$ \\
Glomus mosseae IMA1 & $29.17 \pm 7.90 \mathrm{bc}$ & $12.86 \pm 6.13 \mathrm{a}$ \\
Glomus mosseae NB114 & $20.00 \pm 3.87 \mathrm{abc}$ & $43.83 \pm 14.39 \mathrm{ab}$ \\
Glomus spp. AD 1 & $9.17 \pm 3.00 \mathrm{ab}$ & $75.65 \pm 21.11 \mathrm{ab}$ \\
Scutellospora calospora NC128 & 0 & - \\
\hline Total & $22.71 \pm 2.72$ & $37.01 \pm 6.50$
\end{tabular}

${ }^{\mathrm{a}, \mathrm{b}}$ Values are means $\pm \mathrm{SE}$ of six replicates for each treatment; values in each column not followed by the same letters are significantly different $(P \leq 0.001)$. 
Figure 1. Redundancy analysis biplot showing five AM fungal isolates (Glomus geosporum CI102; Glomus mosseae IMA1, NB114, BEGG25; Glomus spp. AD 1), used as explanatory variables (up-triangles), in order to investigate their influence on four fungal physiological parameters (hyphal length, arbuscular mycorrhizal root colonization, spore density and spore germination) used as response variables (rows).

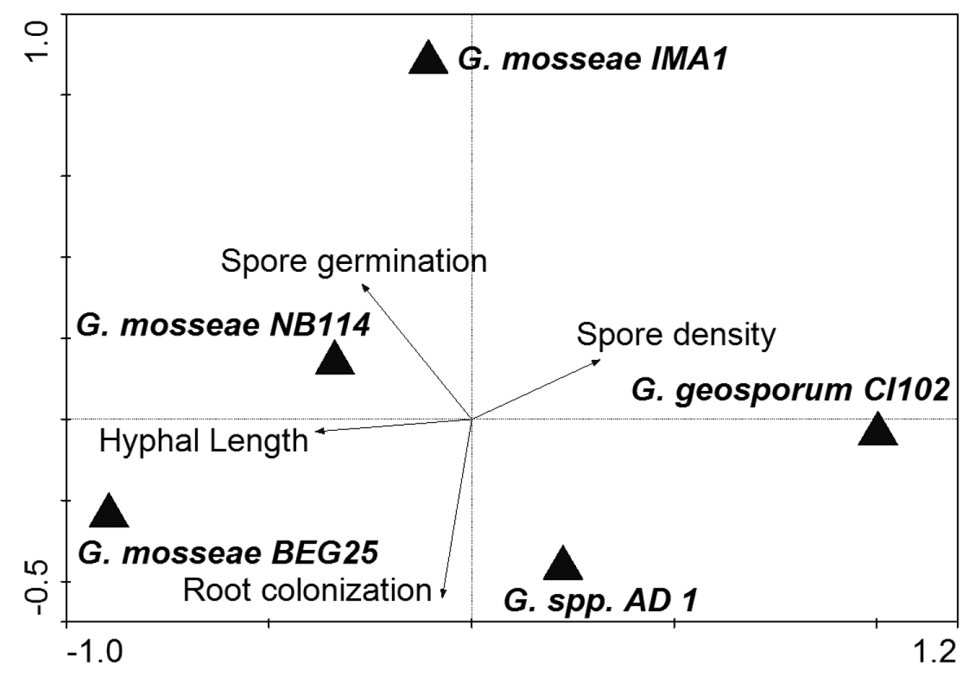

Germination is the first step of AM fungal life cycle and an important character to take into account when selecting endophytes for pratical applications, since it shows a high degree of variation among isolates (Smith and Read, 2008). The environmental parameters influencing spore germination are represented by $\mathrm{pH}$, temperature, moisture, mineral and organic nutrients, presence of host/nonhost plants and microorganisms (Giovannetti, 2000). Interestingly, significant differences were observed within $G$. mosseae species (Tab. 5). Our data confirm previous results on the large variability of spore and sporocarp germination within G. mosseae, both in vivo and in vitro (Giovannetti et al., 2003). The absence of germination of A. spinosa, G. caledonium, G. coronatum and $S$. calospora spores confirms previous data on the erratic germination ability of such species in an in vitro system (Declerck et al., 2005).

Hyphal length per spore or sporocarp ranged between $4.67 \pm 1.41$ and $79.81 \pm 9.73 \mathrm{~mm}$ (G. mosseae FL156 and G. mosseae BEG25, respectively) and the total mean was $37.01 \pm 6.50$ mm (Tab. 5). Significant differences were observed between $G$. etunicatum UK208, $G$. mosseae FL156, G. mosseae IMA1 and $G$. mosseae BEG25 (Table 5).

Germlings of AM fungi are able to elongate and originate a coenocytic mycelial network generally extending no more than 50-200 mm (Giovannetti and Avio, 2002). Our data are comparable with such hyphal lengths, which have been reported to be affected by several vari- ables, such as AM fungal isolates (Hepper and Smith, 1976; Hepper, 1979; Graham, 1982; Siqueira et al., 1982; Gianinazzi-Pearson et al., 1989; Tommerup, 1983; Giovannetti et al. 2003; Bago et al., 1998; Logi et al., 1998), host plants (Giovannetti et al. 1993b) and edaphic conditions (Giovannetti and Avio, 2002; Smith and Read, 2008). Interestingly, we found variability within G. mosseae species, confirming previous data reported by Avio et al. (2009).

\section{Main patterns in AM fungal infectivity traits}

The RDA, performed in order to investigate the influence of AM fungal isolates on infectivity parameters, such as spore production, host root colonization, spore germination and hyphal growth, showed that the identity of the different AM fungi (used as explanatory variables) explained about $60 \%$ (I and II axes) of the whole variance and that their effects on fungal infectivity traits was statistically significant $(P=$ 0.002) (Fig. 1). In detail, Monte Carlo permutation test showed that the infectivity parameters of G. geosporum CI102 and Glomus spp. AD 1, differed significantly and were also different from those of the other fungal isolates ( $G$. mosseae BEG25, IMA1, NB114) $(P<0.05)$. The biplot clearly suggested that variables useful for the detection of the most infective AM fungal isolates are represented by hyphal length, the most discriminating variable on the first axis, and root colonization, the most discriminating variable on the second axis (Fig. 1).

Several authors have previously assessed sin- 
gle or multiple variables in order to evaluate AM fungal infectivity (Giovannetti and Avio, 2002). Here, for the first time, the power of four of the main variables commonly utilized to detect infectivity, was evaluated by using a multivariate approach. Our results showed that root colonization and hyphal length were able to discriminate AM fungi better than spore production and germination, which are affected by environmental factors.

\section{Conclusion}

The utilization of AM fungi in the field primarily relies on the availability of highly infective isolates. Spores and sporocarps are mostly utilised as inoculum sources in laboratory and field experiments, though they show high variability in germination, pre-symbiotic growth and intraradical growth, which greatly affect the infectivity and efficiency of AM propagules. In this work we detected the best parameters for the selection of infective endophytes for field inoculation, which are represented by hyphal length and root colonization.

\section{Acknowledgment}

The authors wish to thank the donors of the AM fungal isolates used in the experiments (Tab. 1).

\section{References}

Avio L., Pellegrino E., Bonari E., Giovannetti M. 2006. Functional diversity of arbuscular mycorrhizal fungal isolates in relation to extraradical mycelial networks. New Phytol., 172:347-357.

Avio L., Cristani C., Strani P., Giovannetti M. 2009. Genetic and phenotypic diversity of geographically different isolates of Glomus mosseae. Can. J. Microbiol., 55:242-253.

Bago B., Azcón-Aguilar C., Goulet A., Piché Y. 1998. Branched absorbing structures (BAS): a feature of the extraradical mycelium of symbiotic arbuscular mycorrhizal fungi. New Phytol., 139:375-388.

Bentivenga S.P., Hetrick B.A.D. 1991. Seasonal and temperature effects on mycorrhizal activity and dependence of cool- and warm-season tallgrass prairie grasses. Can. J. Bot., 70:1596-1602.

Bever J.D., Morton J.B., Antonovics J., Schultz P.A. 1996. Host-dependent sporulation and species diversity of arbuscular mycorrhizal fungi in a mown grassland. Journal of Ecology, 84:71-82.
Black R., Tinker P.B. 1979. The development of endomycorrhizal root systems. II. Effect of agronomic factors and soil conditions on the development of vesicular-arbuscular mycorrhizal infection in barley and on the endophyte spore density. New Phytol., 83:401-413.

Boerner R.E. 1990. Role of mycorrhizal fungus origin in growth and nutrient uptake of Geranium robertianum. Am. J. Bot., 77:483-489.

Burdon J.J. 1987. Diseases and Plant Population Biology. Cambridge University Press, Cambridge.

Carrenho R., Trufem S.F.B., Bononi V.L.R. 2002. Effects of using different host plants on the detected biodiversity of arbuscular mycorrhizal fungi from an agroecosystem. Rev. Bras. Bot., 25:93-101.

Daft M.J., Hogarth B.G. 1983. Competitive interactions amongst four species of Glomus on maize and onion. Trans. Br. Mycol. Soc., 80:339-345.

Declerck S., Strullu D.G., Fortin J.A. (2005). In vitro culture of mycorrhizas. Springer-Verlag Berlin, Heidelberg.

Douds D.D., Galvez L., Bécard G., Kapulnik Y. 1998. Regulation of arbuscular mycorrhizal development by plant host and fugus species alfalfa. New Phytol., 138:27-35.

Fowler N.L., Antonovics J. 1981. Competition and coexistence in a North Carolina grassland. I. Patterns in undisturbed vegetation. J. Ecol., 69:825-841.

Fox L.R., Morrow P.A. 1981. Specialization: species proprerty or local phenomenon? Science, 211:887-893.

Gemma J.N., Koske R.E., Carreiro M. 1989. Seasonal dynamics of selected species of V-A mycorrhizal fungi in a sand dune. Mycol. Res., 92:317-321.

Gianinazzi-Pearson V., Branzanti B., Gianinazzi S. 1989. In vitro enhancement of spore germination and early hyphal growth of a vesicular-arbuscular mycorrhizal fungus by host root exudates and plant flavonoids. Symbiosis, 7:243-255.

Gilden A., Tinker P.B. 1981. A heavy-metal-tolerant strain of a mycorrhizal fungus. Trans. Br. Mycol. Soc., 77:648-649.

Giovannetti M., Mosse B. 1980. An evaluation of techniques for measuring vesicular-arbuscular mycorrhizal infection in roots. New Phytol., 84:489-500.

Giovannetti M. 2000. Spore germination and pre-symbiotic mycelial growth. In: Kapulnik Y., Douds D.D. (eds.): Arbuscular Mycorrhizae: Molecular Biology and Physiology. Kluwer Academic Publishers b.v., The Netherlands, 1-22.

Giovannetti M., Gianinazzi-Pearson V. 1994. Biodiversity in arbuscular mycorrhizal fungi. Mycol. Res., 98:705-715.

Giovannetti M., Avio L. 2002. Biotechnology of Arbuscular Mycorrhizas. In: Khachatourians G.G., Arora D. K. (eds.): Applied Mycology And Biotechnology, Volume 2, Agriculture and Food Production. Elsevier Science b.v., 275-310.

Giovannetti M., Avio L., Sbrana C., Citernesi A.S. 1993a. Factors affecting appressorium development in the vesicular-arbuscular mycorrhizal fungus Glomus 
mosseae (Nicol. \& Gerd.) Gerd. \& Trappe. New Phytol., 123:115-122.

Giovannetti M., Sbrana C., Avio L., Citernesi A.S., Logi C. 1993b. Differential hyphal morphogenesis in arbuscular mycorrhizal fungi during pre-infection stages. New Phytol., 125:587-593.

Giovannetti M., Sbrana C., Strani P., Agnolucci M., Rinaudo V., Avio L. 2003. Genetic diversity of isolates of Glomus mosseae from different geographical areas detected by vegetative compatibility testing and biochemical and molecular analysis. App. Environ. Microbiol., 69:616-624.

Giovannetti M., Schubert A., Cravero M.C., Salutini L. 1988. Spore production by the vesicular-arbuscular mycorrhizal fungus Glomus monosporum as related to host species, root colonization and plant growth enhancement. Biol. Fert. Soil, 6:120-124.

Graham J.H. 1982. Effect of citrus exudates on germination of clamydospores of the vesicular-arbuscular mycorrhizal fungus, Glomus epigaeum. Mycologia, 74:831-835.

Hart M.M., Reader R.J. 2001. Taxonomic basis for variation in the colonization strategy of arbuscular mycorrhizal fungi. New Phytol., 153:335-344.

Hepper C.M. 1979. Germination and growth of Glomus caledonium spores: the effects of inhibitors and nutrients. Soil Biol. Biochem., 11:269-277.

Hepper C.M., Smith G.A. 1976. Observation on the germination of Endogone spores. Trans. Br. Mycol. Soc., $81: 37-45$

Hetrick B.A.D., Wilson G.W.T., Schwab A.P. 1994. Mycorhhizal activity in warm- and cool-season grasses: variation in nutrient-uptake strategies. Can. J. Bot., 72:1002-1008.

Hetrick B.A.D., Bloom J. 1986. The influence of host plant production and colonization ability of vesicular-arbuscular mycorrhizal spores. Mycologia, 78:32-36.

Hung L.L., Sylvia D.M. 1988. Production of vesicular-arbuscular mycorrhizal fungus inoculum in aeroponic culture. Appl. Environ. Microbiol., 54:353-357.

Koomen I., Grace C., Hayman D.S. 1987. Effectiveness of single and multiple mycorrhizal inocula on growth of clover and strawberry plants at two pH's. Soil Biol. Biochem., 19:539-544.

Logi C., Sbrana C., Giovannetti M. 1998. Cellular events involved in survival of individual arbuscular mycorrhizal symbionts growing in the absence of the host. Appl. Environ. Microbiol., 64:3473-3479.

Louis L., Lim G. 1988. Differential response in growth and mycorrhizal colonization of soybean to inoculation with two isolates of Glomus clarum in soils of different $\mathrm{P}$ availability. Plant Soil, 112:37-43.

McGraw A.C., Hendrix J.W. 1984. Host and soil fumigation effects on spore population densities of species of endogonaceous mycorrhizal fungi. Mycologia, 76:122-131.

Moreira M., Nogueira M.A., Tsai S.M., Gomes-da-Costa S.M., Cardoso E.J.B.N. 2007. Sporulation and diversity of arbuscular mycorrhizal fungi in Brazil Pine in the field and in the greenhouse. Mycorrhiza, 17:519-526.

Munkvold L., Kjøller R., Vestberg M., Rosendahl S., Jakobsen I. 2004. High functional diversity within species of arbuscular mycorrhizal fungi. New Phytol., 164:357-364.

Newsham K.K., Fitter A.H., Watkinson A.R. 1995. Multi-functionality and biodiversity in arbuscular mycorrhizas. Trends Ecol. Evol., 10:407-411.

Phillips J.M., Hayman D.S. 1970. Improved procedures for clearing roots and staining parasitic and vesicular-arbuscular mycorrhizal fungi for rapid assesment of infection. Trans. Br. Mycol. Soc., 55:158-160.

Schenck N.C., Kinloch, R.A. 1980. Incidence of mycorrhizal fungi on six field crops in monoculture on newly cleared woodland site. Mycologia, 72:446-456.

Schüßler A., Schwarzott W.C. 2001. A new fungal phylum, the glomeromycota: phylogeny and evolution. Mycol. Res., 105:1413-1421.

Silva F.S.B., Yano-Melo A.M., Brandão J.A.C., Maia L.C. 2005. Sporulation of arbuscular mycorrhizal fungi using Tris-HCL bufefr in addition to nutrient solutions. Braz. J. Microbiol., 36:327-332.

Siqueira J.O., Hubbell D.H., Schenck N.C. 1982. Spore germination and germ tube growth of a vesicular-arbuiscular mycorrhizal fungus in vitro. Mycologia, 74:952-959.

Smith F.A., Jakobsen I., Smith S.E. 2000. Spatial differences in acquisition of soil phosphate between two arbuscular mycorrhizal fungi in symbiosis with Medicago truncatula. New Phytol., 147:357-366.

Smith S.E., Read D.J. 2008. Mycorrhizal Symbiosis, 3nd edition. Academic Press, San Diego, USA.

Snyder M.F., Douds D.D., Galvez L., Phillips J.G., Wagoner P., Drinkwater L., Morton J.B. 2001. Diversity of communities of arbuscular mycorrhizal (AM) fungi present in conventional versus low-input agricultural sites in eastern Pennsylvania, USA. Appl. Soil Ecol., 16:35-48.

Stahl P.D., Smith W.K. 1984. Effects of different geographic isolates of Glomus on the water relations of Agropyron smithii. Mycologia, 76:261-267.

Stahl P.D., Christensen M. 1991. Population variation in the mycorrhizal fungus Glomus mosseae: breadth of environmental tolerance. Mycol. Res., 95:300-307.

Stahl P.D., Christensen M.M., Williams S.E. 1990. Population variation in the mycorrhizal fungus Glomus mosseae: uniform garden experiments. Mycol. Res., 94:1070-1076.

ter Braak C.J.F., Šmilauer P. 2003. CANOCO for Windows Version 4.51, Biometris-Plant Research International Wageningen, The Netherlands.

Tommerup I.C. 1983. Temperature relations of spore germination and hyphal growth of vesicular-arbuscular mycorrhizal fungi in soil. Trans. Br. Mycol. Soc., 81:381-387.

van der Heijden M.G.A., Sanders I.R. 2002. Mycorrhizal ecology: Synthesis and perspectives. Springer-Verlag, New York, Secaucus, NJ. 